\title{
Inheritance Pattern of Temephos Resistance, an Organophosphate Insecticide, in Aedes aegypti (L.)
}

\author{
Vinaya Shetty, Deepak Sanil, and N. J. Shetty \\ Centre for Applied Genetics, Bangalore University, Jnana Bharathi Campus, Bengaluru 560056, India \\ Correspondence should be addressed to N. J. Shetty; shetty_nj@yahoo.co.in
}

Received 22 August 2014; Accepted 5 January 2015

Academic Editor: Norman A. Doggett

Copyright (C) 2015 Vinaya Shetty et al. This is an open access article distributed under the Creative Commons Attribution License, which permits unrestricted use, distribution, and reproduction in any medium, provided the original work is properly cited.

\begin{abstract}
The present paper reports the mode of inheritance of resistance in laboratory induced temephos resistant and susceptible strains of Ae. aegypti. Homozygous resistant and susceptible strains of Ae. aegypti were generated by selective inbreeding at a diagnostic dose of $0.02 \mathrm{mg} / \mathrm{L}$ of temephos. Genetic crosses were carried out between these strains to determine the inheritance pattern of temephos resistance. The log-dosage probit mortality relationships and degree of dominance $(D)$ were calculated. The dosage-mortality $(d-m)$ line of the $F_{1}$ generation was nearer to the resistant parent than the susceptible one. The " $D$ " value was calculated as 0.15 indicating that the temephos resistant gene is incompletely dominant. The $d-m$ lines of the $F_{2}$ generation and progeny from the backcross exhibited clear plateaus of mortality across a range of doses indicating that temephos resistance is controlled by a single gene. Comparison of the mortality data with the theoretical expectations using the $\chi^{2}$ test revealed no significant difference, confirming a monogenic pattern of inheritance. In conclusion, the study provides evidence that the temephos resistance in Ae. aegypti follows an incompletely dominant and monogenic mode of inheritance.
\end{abstract}

\section{Introduction}

Aedes aegypti (Diptera:Culicidae), the principal vector of dengue fever (DF) and its more severe form dengue hemorrhagic fever (DHF), is of significant public health concern in tropical, subtropical, and temperate regions of the world $[1,2]$. The global prevalence of the disease has grown dramatically in recent decades. World Health Organization (WHO) estimates about two-fifths of the world's populations at risk of dengue infection [3]. Vector control has been a significant strategy to control mosquito-borne diseases worldwide. Currently, chemical treatment is the most important component in an integrated campaign to achieve effective vector control [4]. The repeated use of insecticides to control the mosquito population is believed to be the main source of resistance in these vectors $[5,6]$ and is considered as a recent evolutionary adaptation to changes in the environment, arising in less than a century, in response to the repetitive use of chemical insecticides [7].

Ae. aegypti is an extremely successful species when it comes to the ability to disperse and to adapt to varying environments. Currently the most feasible, effective, and practical method of control of this vector species is through the use of insecticides [8]. Temephos, an organophosphate (OP) insecticide, is recommended as a larvicide by World Health Organization (WHO) to control mosquitoes, midge, blackfly, and other insects [2]. In India, it has been recommended for controlling larval stages of mosquitoes and its use is patronized by the Government of India under their National Vector Borne Diseases Control Programme (NVBDCP), Defense Services, and so forth. It is also used in several other countries like Brazil, USA, South Africa, and Southeast Asian countries for mosquito control programme $[2,9]$. Temephos is widely used for the control of Aedes. However, its indiscriminate use has led to development of resistance against temephos, in Cambodia, federal districts of Brazil, and Southeast Asia [9-14]. Studies have shown temephos to be effective in controlling Ae. aegypti in several parts of India $[15,16]$. However, different populations of Bangalore and Mumbai have shown a high tolerance to temephos, when compared with the WHO recommended diagnostic dose $[17,18]$. Inherited resistance to some of 
the insecticides such as DDT and Dieldrin in Ae. aegypti has been identified and reported $[19,20]$. Understanding the mode of inheritance helps in resistance detection, monitoring, modeling, and risk assessment [21]. Hence, the present study is of considerable significance in deciphering the inheritance pattern of temephos resistance in the said species.

Resistance mechanism such as increased sequestration or detoxification causes a reduced dose of the insecticide at target site, while reduced target site sensitivity causes ineffective binding of the insecticide at a given dose [2224]. Acquisitions of resistance to insecticides can be used to gauge the microevolution process, because, as a result of this compelling selection pressure, the rate of evolution is higher [25]. Considering that such acquired resistance is the reflection of changes in the genotypic architecture of natural populations, investigating the genetic basis of resistance is a prerequisite to understand the evolution of this phenomenon [26]. Besides the evolutionary approach, there is also an urgent need to improve our knowledge of the mechanisms governing resistance development. The present paper describes the mode of inheritance in laboratory induced temephos resistant and temephos susceptible strains in Ae. aegypti.

\section{Materials and Methods}

2.1. Mosquito Rearing. Aedes aegypti used in the present study was originally collected from Jaya Prakashnarayan Nagar (JPN), Bangalore, India. The larvae and adults were reared in an insectary maintained at $25 \pm 1^{\circ} \mathrm{C}$, relative humidity $75 \pm 5 \%$, and a 14 -hour photoperiod [27]. Adults were maintained in cages of iron frames covered by cotton net cloth and fed on $10 \%$ sucrose solution in a jar with a cotton wick. Polypropylene cups ( 3 " diameter) lined with filter paper and containing clean tap water were placed inside the cages for oviposition. Powdered mixture of yeast tablets (Geo Pharmaceuticals, Bangalore) and dog biscuits (Pedigree, Mars Industries, Hyderabad) were provided as larval diet. All mosquitoes used in the experiments were reared at a density of around 600 larvae per tray $(25 \times 30 \mathrm{~cm})$ containing approximately 2 litres of water (water depth $2 \mathrm{~cm})$.

2.2. Insecticide. Temephos (Abate) (50\% TC), an organophosphate insecticide, with molecular formula $\mathrm{C}_{16} \mathrm{H}_{20} \mathrm{O}_{6} \mathrm{P}_{2} \mathrm{~S}_{3}$, and International Union for Pure and Applied Chemistry (IUPAC) name $O, O, O^{\prime}, O^{\prime}$-tetramethyl $O, O^{\prime}$-thiodi-p-phenylene bis(phosphorothioate), was used in the present study.

2.3. Larval Bioassay. Denatured alcohol ( $98 \mathrm{~mL}$ of absolute alcohol and $2 \mathrm{~mL}$ of methyl ethyl ketone) was used as the solvent to prepare a range of stock concentrations of temephos $[28,29]$. The initial phase of the study involved exposing 25 early fourth instar larvae contained in $500 \mathrm{~mL}$ glass beakers with $1 \mathrm{~mL}$ of the designated concentration of insecticide and made up to $250 \mathrm{~mL}$ with dechlorinated tap water. A range of increasing concentrations was used to get the mortality between $2 \%$ and $98 \%$ after a $24 \mathrm{~h}$ exposure. Each concentration had four replicates. Controls were set up identically using $1 \mathrm{~mL}$ of ethanol to $249 \mathrm{~mL}$ of tap water, without the insecticide. Mortality in each case was recorded after $24 \mathrm{hrs}$ of exposure to the insecticide and the mortality percentage was calculated by including both dead and moribund larvae as per WHO guidelines [28, 29].

\subsection{Development of Temephos Resistant and Susceptible Strains}

Temephos Resistant (TR) Strain. According to the procedure of WHO, susceptibility studies were carried out for the late third instar larvae from the isofemale lines of JPN strain with WHO diagnostic dose of $0.02 \mathrm{mg} / \mathrm{L}[28,29]$. Twenty-four hours later, the surviving larvae from the test showing lowest mortality of isofemale population were collected, maintained separately, and used for inbreeding. Mass treatment was followed to treat the larvae of successive generations, and the surviving ones were inbred to obtain further generations. The process of selective inbreeding was repeated by gradually increasing the dose from subdiagnostic concentrations to $0.02 \mathrm{mg} / \mathrm{L}$ until a pure homozygous resistant (100\% survival) strain was established.

Temephos Susceptible (TS) Strain. JPN strain was used to select homozygous susceptible strain. About $50 \%$ of the larvae obtained from the isofemales of JPN strain were treated to the diagnostic dose of $0.02 \mathrm{mg} / \mathrm{L}$. Untreated larvae of the batch showing the highest percentage of mortality were selected for inbreeding and the selection procedure was repeated until getting a pure homozygous susceptible strain (100\% mortality).

2.5. Genetic Studies of TR. Twenty-five pairs of freshly emerged males and females of the homozygous resistant $(R)$ and susceptible $(S)$ strains were used, to carry out reciprocal genetic crosses $\left(R{ }^{\star} \times S \%\right.$ and $\left.R+\times S_{\circlearrowleft}^{\star}\right)$. A part of the $F_{1}$ individuals was inbred to get $F_{2}$ generation and the remaining mosquitoes were backcrossed $\left(F_{1} \times S\right)$ by reciprocal cross of both male and female progeny to parental type $(S)$. Apart from this, the late third instar larvae from all the crosses were subjected to larval bioassays. The log-dosage probit mortality relationships were recorded for all the genetic crosses [30-33] and the degree of dominance $(D)$ was calculated using Stone's formula [34]:

$$
D=\frac{2 X_{2}-X_{1}-X_{3}}{X_{1}-X_{3}}
$$

where $D$ is the degree of dominance and $X_{1}, X_{2}$, and $X_{3}$ are the logarithms of the $\mathrm{LC}_{50}$ (concentration that produces $50 \%$ mortality) values of the resistant, $F_{1}$ hybrid, and susceptible strains, respectively.

The value calculated for $D$ indicates whether the trait is completely dominant $(D=1)$, incompletely dominant $(0<$ $D<1)$, incompletely recessive $(-1<D<0)$, or completely recessive $(D=-1)$. 
TABLE 1: Inheritance pattern of temephos resistance in Aedes aegypti.

\begin{tabular}{|c|c|c|c|c|c|c|c|c|}
\hline \multirow{2}{*}{ S. number } & \multirow{2}{*}{ Genetic crosses } & \multirow{2}{*}{ Number of females tested } & \multirow{2}{*}{ Number of larvae tested ${ }^{* *}$} & \multicolumn{2}{|c|}{ Resistant } & \multicolumn{2}{|c|}{ Susceptible } & \multirow{2}{*}{$\chi^{2}$} \\
\hline & & & & Alive & $\%$ & Dead & $\%$ & \\
\hline & Parental & & & & & & & \\
\hline 1 & $S_{0} \times \times$ S & 25 & 1824 & - & - & 1824 & 100 & - \\
\hline \multirow[t]{2}{*}{2} & $R \widehat{O} \times R$ 우 & 25 & 1707 & 1707 & 100 & - & - & - \\
\hline & $F_{1}$ generation & & & & & & & \\
\hline 3 & $S o ̛$ × R & 25 & 1744 & 992 & 56.88 & 752 & 43.11 & $0.94^{*}$ \\
\hline \multirow[t]{2}{*}{4} & $R{ }^{\hat{*}} \times S Q$ & 25 & 1697 & 1014 & 59.75 & 683 & 40.24 & $1.90^{*}$ \\
\hline & Backcrosses & & & & & & & \\
\hline 5 & $S_{0} \times F_{1}$ ㅇ $(\operatorname{cross} 3)$ & 25 & 1762 & 968 & 54.93 & 794 & 45.06 & $0.48^{*}$ \\
\hline 6 & $S @ \times F_{1} \widehat{0}(\operatorname{cross} 3)$ & 25 & 1809 & 1032 & 57.04 & 777 & 42.95 & $0.99^{*}$ \\
\hline 7 & $S_{0} \times F_{1}$ q $(\operatorname{cross} 4)$ & 25 & 1794 & 1022 & 56.96 & 772 & 43.03 & $0.97^{*}$ \\
\hline \multirow[t]{2}{*}{8} & 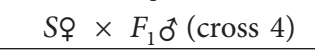 & 25 & 1846 & 996 & 53.95 & 850 & 46.04 & $0.31^{*}$ \\
\hline & $F_{2}$ generation & & & & & & & \\
\hline 9 & $F_{1} \widehat{0} \times F_{1}$ 우 $(\operatorname{cross} 3)$ & 25 & 1872 & 1038 & 55.44 & 834 & 44.55 & $0.59^{*}$ \\
\hline 10 & $F_{1} 0^{\star} \times F_{1}$ 우 ( $\left.\operatorname{cross} 4\right)$ & 25 & 1832 & 1097 & 59.71 & 730 & 40.28 & $1.88^{*}$ \\
\hline
\end{tabular}

$R$ : resistant; $S$ : susceptible. ${ }^{*}$ Nonsignificant $(P>0.05)$.

${ }^{* *}$ Late third instar larvae exposed to $0.02 \mathrm{mg} / \mathrm{L}$ for $24 \mathrm{~h}$.

The expected percent mortality for cross 1 is 100 , cross 2 is zero, and crosses $3-10$ is $50 \%$.

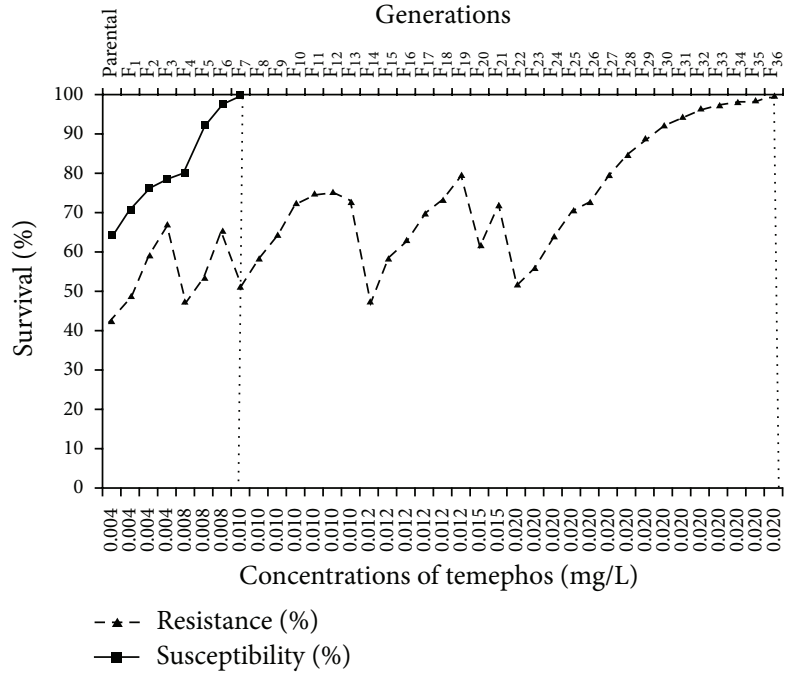

FIGURE 1: Development of homozygous resistance and susceptible strains of Aedes aegypti in each generation. The line showing the $100 \%$ susceptibility and resistance after 7 and 36 generations at 0.01 and $0.02 \mathrm{mg} / \mathrm{L}$, respectively.

2.6. Data Analysis. The $\mathrm{LC}_{50}$ and $\mathrm{LC}_{90}$ values of the bioassay were calculated by subjecting the log-dosage-mortality data to probit analysis [31]. The dosage-mortality lines ( $d$ - $m$ lines) which give an insight into the mode of inheritance were constructed. Microsoft Office Excel 2007 was employed for data analysis. Controls were set up to determine natural mortality and Abbot's formula was used to correct the mortality data from larvicidal assays [35]. Chi square $\left(\chi^{2}\right)$ values were calculated using the procedure of Bailey [36].

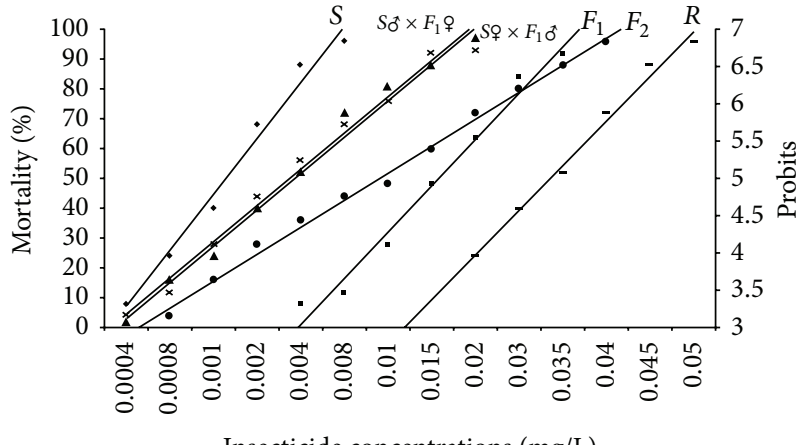

FIGURE 2: Dosage-mortality relationships of the temephos resistance and susceptible strains of Aedes aegypti. The dosage-mortality lines were constructed for the larvae from all the crosses including

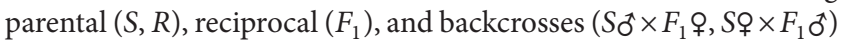
and also for $F_{2}$ generation.

\section{Results}

Homozygous resistant and susceptible strains of Ae. aegypti were synthesized in laboratory by continuous selection and inbreeding for 36 and 7 generations, respectively, using $0.02 \mathrm{mg} / \mathrm{L}$ diagnostic dose of temephos (Figure 1). Results of these crosses are presented in Table 1. Crosses 1 and 2 established homozygous resistant and susceptible strains, showing clear homozygosity to resistance (100\% survival) and susceptibility (100\% mortality), respectively. The $\mathrm{LC}_{50}$ of resistant strain was 56.25 times greater than that of susceptible strain. Bioassay of the parental strains with temephos yielded a straight $d-m$ line, indicating the purity of gamete for resistance and susceptibility (Figure 2). Reciprocal crosses (crosses 3 and 4) between the resistant and susceptible strains 
resulted in $F_{1}$ hybrids which exhibit $56.88 \%$ and $59.75 \%$ of resistance, respectively. Backcrossing the $F_{1}$ hybrids from crosses 3 and 4, to their homozygous parent line, yielded progeny with $54.93 \%, 57.04 \%, 56.96 \%$, and $53.95 \%$ resistance, respectively (crosses $5,6,7$, and 8 ). $F_{2}$ progeny from crosses 9 and 10 showed $55.44 \%$ and $59.71 \%$ resistance, respectively, using the data derived from these crosses, and the log $d-m$ lines (Figure 2) were constructed. The $d-m$ lines of backcrosses were found to be in between susceptible and $F_{1}$ hybrids (Figure 2). As observed in Figure 2, the $d-m$ line of $F_{1}$ was inclined towards the resistant line and " $D$ " value was calculated to be 0.15 . Using Chi square test, the mortality data of the progeny from the backcrosses were compared with theoretical expectations and tested for monogenic inheritance. Incomplete dominance was apparent in the progeny of crosses 3 and 4, considering that they exhibited slightly over $50 \%$ resistance and the fact that the position of the log dose probit line was towards the resistant parent.

The expected segregation of the backcross of the RS (heterozygous) to the $S$ (homozygous susceptible) strain for monogenic Mendelian inheritance was calculated using the formula [37]

$$
x(B C)=\left(\frac{1}{2}\right) a_{1}(R S)+\left(\frac{1}{2}\right) a_{1}(S),
$$

where $x$ is expected response of the backcross at a particular dose and $a_{1}$ and $a_{2}$ are observed responses of $R S$ and $S$ populations at that dose.

In this instance, at the diagnostic dose, a $50 \%$ survival is expected in the backcrosses, since the mortality of all susceptible individuals $(S)$ would leave behind 50\% heterozygotes in the progeny. Accordingly, $50 \%$ survival is observed in the crosses $5,6,7$, and 8 with slight deviations which are nonsignificant at $P<0.05$. Applying the same principle, the expected $F_{2}$ segregation was calculated using formula [37]

$$
x\left(F_{2}\right)=\left(\frac{1}{4}\right) a_{1}(R)+\left(\frac{1}{2}\right) a_{2}(R S)+\left(\frac{1}{4}\right) a_{3}(S),
$$

where $x$ is the expected response of $F_{2}$ for a particular dose and $a_{1}, a_{2}$, and $a_{3}$ are the observed responses of the resistant $(R)$, the hybrid $(R S)$, and susceptible $(S)$ populations to that dose.

In the $F_{2}$ generation, the expected outcome is $50 \%$ susceptible/resistance. The observed resistance in both the $F_{2}$ crosses (9 and 10) displayed slight deviations from the expected 50\%, with no significance at $P<0.05$. The "resistance" trait can be termed monogenic if the $d-m$ line of $F_{2}$ or the backcross exhibits a distinct horizontal field of mortality across the increasing magnitude of doses. Two marked inflections in the $d-m$ lines dividing the $F_{2}$ curve at point at $0.008 \mathrm{mg} / \mathrm{L}$ indicate the mortality of the homozygous susceptible individuals $(S)$ and the second inflection point at $0.03 \mathrm{mg} / \mathrm{L}$ indicates the complete mortality of the heterozygous individuals $(R S)$. In addition, one inflection point was observed at $0.004 \mathrm{mg} / \mathrm{L}$ in backcross, indicating the complete elimination of $S$ individuals leaving behind $R S$ individuals (Figure 3).

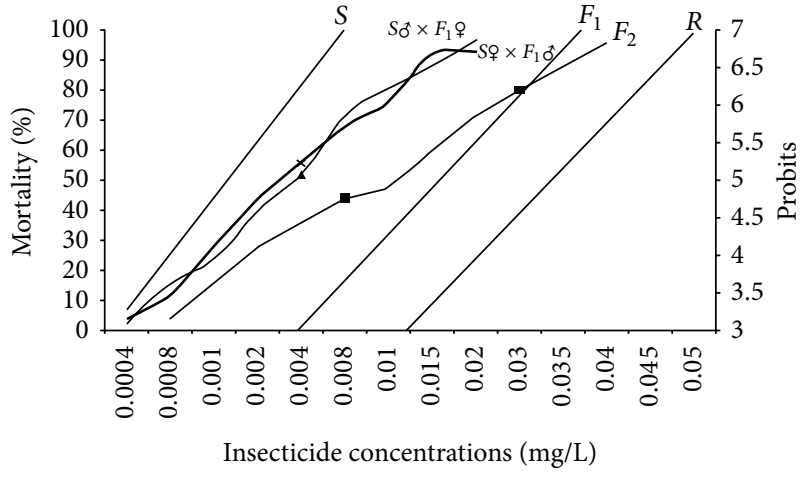

FIGURE 3: Dosage-mortality relationships of the TR and TS strains of Aedes aegypti showing break/inflection points on $d-m$ lines of $F_{2}$ and backcrosses. The $F_{2}$ line showed two inflection points at $0.008 \mathrm{mg} / \mathrm{L}$ and $0.03 \mathrm{mg} / \mathrm{L}$, indicating the cessation of $S$ individuals and $R S$ individuals, respectively. Further the backcross lines also showed one inflection point each at $0.004 \mathrm{mg} / \mathrm{L}$ indicating complete mortality of $S$ individuals leaving behind only $R S$ individuals signifying monogenic inheritance.

\section{Discussion}

The present investigation reveals the mode of inheritance of temephos resistance in Ae. aegypti. The $d-m$ responses of the parental strains were characterized by straight lines, indicating the homogenous nature for resistance and susceptibility. The $F_{1}$ offspring also displayed a straight $d-m$ line, confirming homozygosity of the resistance and susceptible genes involved [38]. The $d-m$ line for $F_{1}$ was found in the middle of that of the resistant and susceptible strains clearly demonstrating a heterozygous nature of temephos resistance in $F_{1}$. Additionally, the calculated value for the degree of dominance $(D)$ also suggests an incompletely dominant pattern of inheritance for resistance to temephos. The response of $F_{1}$ hybrids to the diagnostic concentration was similar in both the crosses, which indicated that a single gene was responsible for conferring resistance to temephos. The observed $F_{2}$ mortality closely approximated that expected from a $1: 2: 1$ ratio of the $S: R S: R$ types. Also, the backcrosses $\left(F_{1} \times S\right)$ were found to be almost in a ratio $1: 1$ of resistant to susceptible individuals. Thus, via both these crosses, the trait of temephos resistance appears to follow a monogenic pattern of inheritance. It is perhaps noteworthy that prior studies on Anopheles stephensi have reported similar genetic patterns of inheritance to several classes of insecticides [39, 40]. Resistance controlled by a single gene develops and spreads much more rapidly when compared to polygenic resistance $[41,42]$. The resistance rapidly extends to new areas through migration of the resistant insect [43]. Studies on the nature of insecticide resistance have shown that the phenomenon is due to preadaptations which usually involve single gene alleles and that the emergence of insecticide resistant strains is thus a consequence of Darwinian selection [44].

The results obtained from the present work could improve our understanding of the rate of resistance development and mode of inheritance of the temephos resistance gene 
involved. The evidence for the simple Mendelian pattern of inheritance is based on log-dosage probit curves and agreement of the observed responses to those that may be expected in the case of monofactorial inheritance. Understanding of resistance mechanisms is crucial for developing novel strategies to circumvent and delay resistance development, controlling resistant mosquitoes, and thus ultimately bringing down the prevalence of mosquito-borne diseases. Characterizing the genes and regulatory mechanisms involved in resistance may pave the way to advanced methods of studying resistance, eventually leading to the discovery of the genes responsible for insecticide resistance [45].

Furthermore, this study can be helpful to determine any cross resistance to other groups of insecticides and understand the permanence of the resistance through succeeding generations upon removal of selection pressure. The present investigation elucidates the mode of inheritance of the temephos resistance gene in the said species, which is an excellent genetic marker for Ae. aegypti. Such genes are extremely useful in conducting basic and applied genetic research such as synthesis of genetic sexing strains as conditional lethal for the preferential exclusion of females during early developmental stages [46]. Moreover the characterization of single gene, which can be located on the chromosome by discovering linkage with mutant markers and which can be associated with specific detoxification enzyme, allows understanding of the resistance situation in the field and points the way to countermeasures based on remedial insecticides.

In conclusion, the ratios $1: 2: 1$ and $1: 1$, along with the conspicuous inflections in the $d-m$ lines, in the $F_{2}$ of the $R \times S$ cross and the progeny of the backcross, provide evidence for the fact that inheritance of resistance to temephos in $A e$. aegypti is monofactorial. Moreover the value of the degree of dominance $(D)$ and the location of $F_{1}$ line with respect to that of the resistant line suggest that the mode of inheritance of temephos resistance in the said species is monogenic and incompletely dominant in nature.

\section{Conflict of Interests}

The authors declare that they do not have any conflict of interests.

\section{Acknowledgments}

Vinaya Shetty and Deepak Sanil are grateful to the Poornaprajna Institute of Scientific Research (PPISR), Bidalur Campus, Devanahalli, for research fellowships. The authors also acknowledge the University Grants Commission (UGC) and Department of Science and Technology (DST), New Delhi, for financial assistance.

\section{References}

[1] D. J. Gubler, "Dengue and dengue hemorrhagic fever," Clinical Microbiology Reviews, vol. 11, no. 3, pp. 480-496, 1998.

[2] World Health Organization, Dengue: Guidelines for Diagnosis, Treatment, Prevention and Control, World Health Organization,
Geneva, Switzerland, 2009, http://whqlibdoc.who.int/publications/2009/9789241547871_eng.pdf.

[3] S. Murrell, S.-C. Wu, and M. Butler, "Review of dengue virus and the development of a vaccine," Biotechnology Advances, vol. 29, pp. 239-247, 2011.

[4] World Health Organization, "Dengue/dengue haemorrhagic fever," Weekly Epidemiological Record, vol. 75, pp. 193-200, 2000.

[5] M. Balkew, M. Ibrahim, L. L. Koekemoer et al., "Insecticide resistance in Anopheles arabiensis (Diptera: Culicidae) from villages in central, northern and south west Ethiopia and detection of kdr mutation," Parasites and Vectors, vol. 3, no. 1, article 40, 2010.

[6] S. Marcombe, R. B. Mathieu, N. Pocquet et al., "Insecticide resistance in the dengue vector aedes aegypti from martinique: distribution, mechanisms and relations with environmental factors," PLoS ONE, vol. 7, no. 2, Article ID e30989, 2012.

[7] K. Karunamoorthi and S. Sabesan, "Insecticide resistance in insect vectors of disease with special reference to mosquitoes: a potential threat to global public health," Health Scope, vol. 2, no. 1, pp. 4-18, 2013.

[8] S. N. Tikar, A. Kumar, G. B. K. S. Prasad, and S. Prakash, "Temephos-induced resistance in Aedes aegypti and its crossresistance studies to certain insecticides from India," Parasitology Research, vol. 105, no. 1, pp. 57-63, 2009.

[9] M. D. S. Laurentino de Carvalho, E. Dutra Caldas, N. Degallier et al., "Susceptibility of Aedes aegypti larvae to the insecticide temephos in the Federal District, Brazil," Revista de Saude Publica, vol. 38, no. 5, pp. 623-629, 2004.

[10] C. D. Chen, W. A. Nazni, H. L. Lee, and M. Sofian-Azirun, "Susceptibility of Aedes aegypti and Aedes albopictus to temephos in four study sites in Kuala Lumpur City Center and Selangor State, Malaysia," Tropical biomedicine, vol. 22, no. 2, pp. 207-216, 2005.

[11] K. A. Polson, S. C. Rawlins, W. G. Brogdon, and D. D. Chadee, "Organophosphate resistance in trinidad and tobago strains of Aedes aegypti," Journal of the American Mosquito Control Association, vol. 26, no. 4, pp. 403-410, 2010.

[12] C. Faraj, E. Adlaoui, M. Elkohli, T. Herrak, B. Ameur, and F. Chandre, "Review of temephos discriminating concentration for monitoring the susceptibility of anopheles labranchiae (Falleroni, 1926), malaria vector in Morocco," Malaria Research and Treatment, vol. 2010, Article ID 126085, 5 pages, 2010.

[13] T. Chareonviriyahpap, B. Aum-Aung, and S. Ratanatham, "Current insecticide resistance patterns in mosquito vectors in Thailand," Southeast Asian Journal of Tropical Medicine and Public Health, vol. 30, no. 1, pp. 184-194, 1999.

[14] P. Paeporn, N. Komalamisra, V. Deesin, Y. Rongsriyam, Y. Eshita, and S. Thongrungkiat, "Temephos resistance in two forms of Aedes aegypti and its significance for the resistance mechanism," Southeast Asian Journal of Tropical Medicine and Public Health, vol. 34, no. 4, pp. 786-792, 2003.

[15] R. Katyal, P. Tewari, S. J. Rahman, H. R. Pajni, K. Kumar, and K. S. Gill, "Susceptibility status of immature and adult stages of Aedes aegypti against conventional insecticides in Delhi, India," Dengue Bulletin, vol. 25, pp. 84-87, 2001.

[16] A. K. Mukhopadhyay, S. K. Patnaik, and P. Satya Babu, "Susceptibility status of some culicine mosquitoes to insecticides in Rajahmundry town of Andhra Pradesh, India," Journal of Vector Borne Diseases, vol. 43, no. 1, pp. 39-41, 2006.

[17] V. Shetty, D. Sanil, and N. J. Shetty, "Insecticide susceptibility status in three medically important species of mosquitoes, Anopheles stephensi, Aedes aegypti and Culex quinquefasciatus, 
from Bruhat Bengaluru Mahanagara Palike, Karnataka, India," Pest Management Science, vol. 69, no. 2, pp. 257-267, 2013.

[18] K. Kumar, A. K. Sharma, M. Sarkar, A. Chauhan, and R. Sharma, "Surveillance of Aedes aegypti (L.) mosquitoes in Mumbai international seaport (India) to monitor potential global health risks," Journal of Insects, vol. 2014, Article ID 951015, 5 pages, 2014.

[19] W. Z. Cooker, "The inheritance of DDT-resistance in Aedes aegypti," Annals of Tropical Medicine and Parasitology, vol. 52, pp. 443-455, 1958.

[20] A. M. Guneidy, "Dieldrin-resistance in a strain of Aedes aegypti (L.) from Puerto Rico," Bulletin of Entomological Research, vol. 55, no. 3, pp. 519-526, 1964.

[21] A. H. Sayyed, R. Haward, S. Herrero, J. Ferré, and D. J. Wright, "Genetic and biochemical approach for characterization of resistance to Bacillus thuringiensis toxin CrylAc in a field population of the diamondback moth, Plutella xylostella," Applied and Environmental Microbiology, vol. 66, no. 4, pp. 1509-1516, 2000.

[22] J. G. Scott, "Investigating mechanisms of insecticide resistance: methods, strategies, and pitfalls," in Pesticide Resistance in Arthropods, R. T. Roush and B. E. Tabashnik, Eds., pp. 39-57, Chapman \& Hall, New York, NY, USA, 1990.

[23] R. Feyereisen, "Molecular biology of insecticide resistance," Toxicology Letters, vol. 82-83, pp. 83-90, 1995.

[24] M. Taylor and R. Feyereisen, "Molecular biology and evolution of resistance to toxicants," Molecular Biology and Evolution, vol. 13, no. 6, pp. 719-734, 1996.

[25] J.-C. Bouvier, R. Buès, T. Boivin, L. Boudinhon, D. Beslay, and B. Sauphanor, "Deltamethrin resistance in the codling moth (Lepidoptera: Tortricidae): inheritance and number of genes involved," Heredity, vol. 87, no. 4, pp. 456-462, 2001.

[26] R. T. Roush and J. C. Daly, "The role of population genetics in resistance research and management," in Pesticide Resistance in Arthropods, R. T. Roush and B. E. Tabashnik, Eds., pp. 97-152, Chapman and Hall, London, UK, 1990.

[27] N. J. Shetty, "Chromosomal translocations and inherited semisterility in the malaria vector Anopheles fluviatilis-James," Indian Journal of Malariology, vol. 20, pp. 45-47, 1983.

[28] World Health Organization, Instructions for Determining the Susceptibility or Resistance of Mosquito Larvae to Insecticides, WHO/VBC/81.807, 1981.

[29] World Health Organization, "Guidelines for laboratory and field testing of mosquito larvicides," Tech. Rep. WHO/CDS/ WHOPES/GCDPP/2005.13, World Health Organization, 2005.

[30] G. P. Georghiou, "Genetics of resistance to insecticides in houseflies and mosquitoes," Experimental Parasitology, vol. 26, no. 2, pp. 224-255, 1969.

[31] D. J. Finney, Probit Analysis, Cambridge University Press, Cambridge, UK, 3rd edition, 1971.

[32] T. M. Priester and G. P. Georghiou, "Penetration of permethrin and knockdown in larvae of pyrethroid resistant and susceptible strains of the Southern House mosquito," Journal of Economic Entomology, vol. 73, no. 1, pp. 165-167, 1980.

[33] M. B. Mazzarri and G. P. Georghiou, "Characterization of resistance to organophosphate, carbamate, and pyrethroid insecticides in field populations of Aedes aegypti from Venezuela," Journal of the American Mosquito Control Association, vol. 11, no. 3, pp. 315-322, 1995.

[34] B. F. Stone, "A formula for determining degree of dominance in case of monofactorial inheritance of resistance to chemicals,"
Bulletin of the World Health Organization, vol. 38, no. 2, pp. 325326, 1968.

[35] W. S. Abbott, "A method of computing the effectiveness of an insecticide," Journal of Economic Entomology, vol. 18, no. 2, pp. 265-267, 1925.

[36] N. T. J. Bailey, Statistical Methods in Biology, English Universities Press, London, UK, 1959.

[37] G. P. Georghiou and M. J. Garber, "Studies on the inheritance of carbamate-resistance in the housefly (Musca domestica L.)," Bulletin of the World Health Organization, vol. 32, no. 2, pp. 181196, 1965.

[38] M. Raymond, N. Pasteur, and G. P. Georghiou, "Inheritance of chlorpyrifos resistance in Culex pipiens L. (diptera: culicidae) and estimation of the number of genes involved," Heredity, vol. 58, pp. 351-356, 1987.

[39] D. Sanil and N. J. Shetty, "Genetic study of propoxur resistance-a carbamate insecticide in the malaria mosquito, Anopheles stephensi Liston," Malaria Research and Treatment, vol. 2010, Article ID 502824, 6 pages, 2010.

[40] T. P. N. H. Prasad and N. J. Shetty, "Autosomal inheritance of alphamethrin, a synthetic pyrethroid, resistance in Anopheles stephensi-liston, a malaria mosquito," Bulletin of Entomological Research, vol. 103, no. 5, pp. 547-554, 2013.

[41] B. E. Tabashnik, "Computer stimulation as a tool for pesticide resistance management," in Pesticide Resistance: Strategies and Tactics for Management, pp. 195-203, National Academy Press, Washington, DC, USA, 1986.

[42] R. T. Roush and J. A. McKenzie, "Ecological genetics of insecticide and acaricide resistance," Annual Review of Entomology, vol. 32, pp. 361-380, 1987.

[43] I. Denholm, G. J. Devine, and M. S. Williamson, "Insecticide resistance on the move," Science, vol. 297 , no. 5590 , pp. $2222-$ 2223, 2002.

[44] World Health Organization, "Genetics of vectors and insecticide resistance," World Health Organization Technical Report Series 268, 1964.

[45] N. Liu, Q. Xu, F. Zhu, and L. Zhang, "Pyrethroid resistance in mosquitoes," Insect Science, vol. 13, no. 3, pp. 159-166, 2006.

[46] N. J. Shetty, "Genetic sexing system for the preferential elimination of females in Culex quinquefasciatus," Journal of the American Mosquito Control Association, vol. 3, no. 1, pp. 84-86, 1987. 

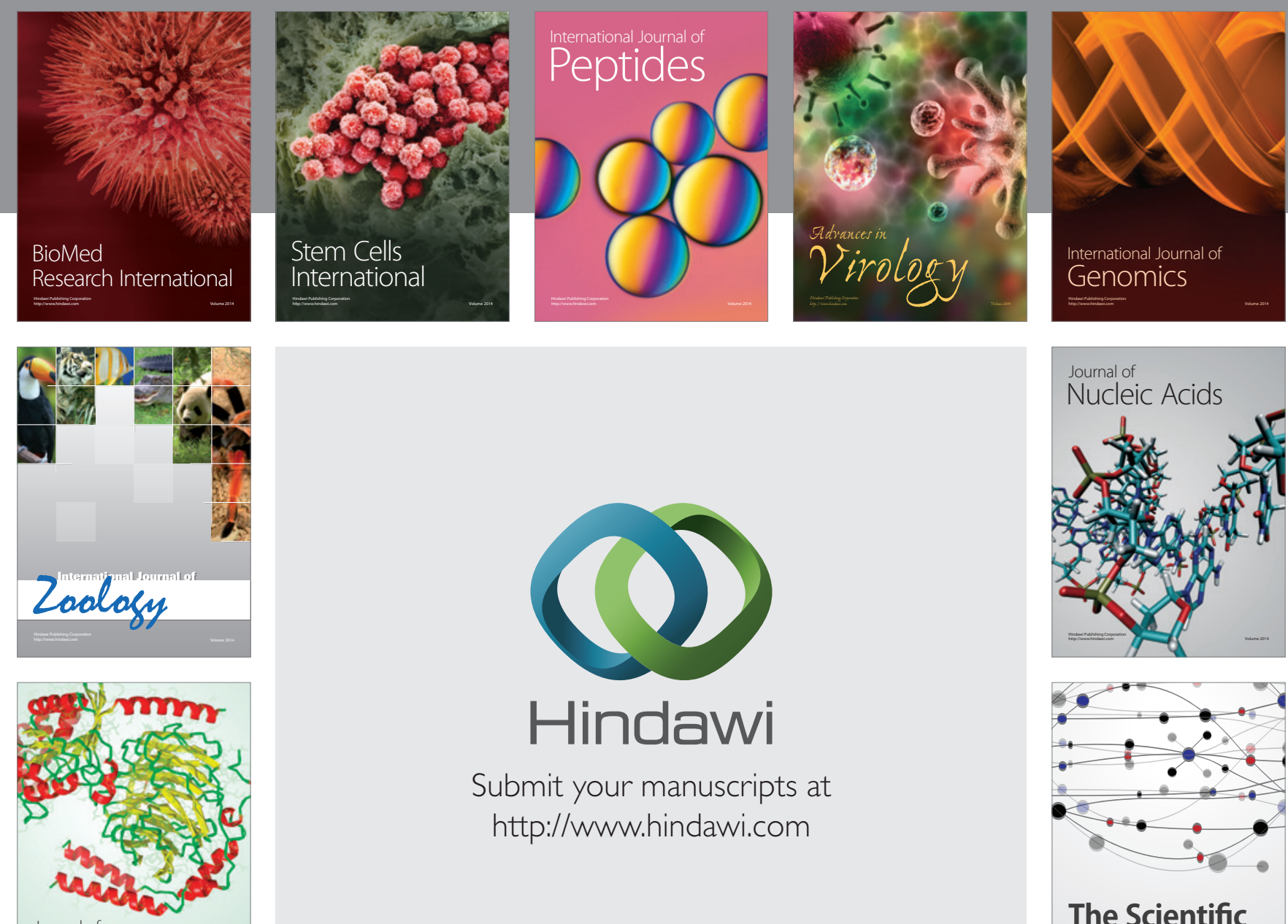

Submit your manuscripts at

http://www.hindawi.com

Journal of
Signal Transduction
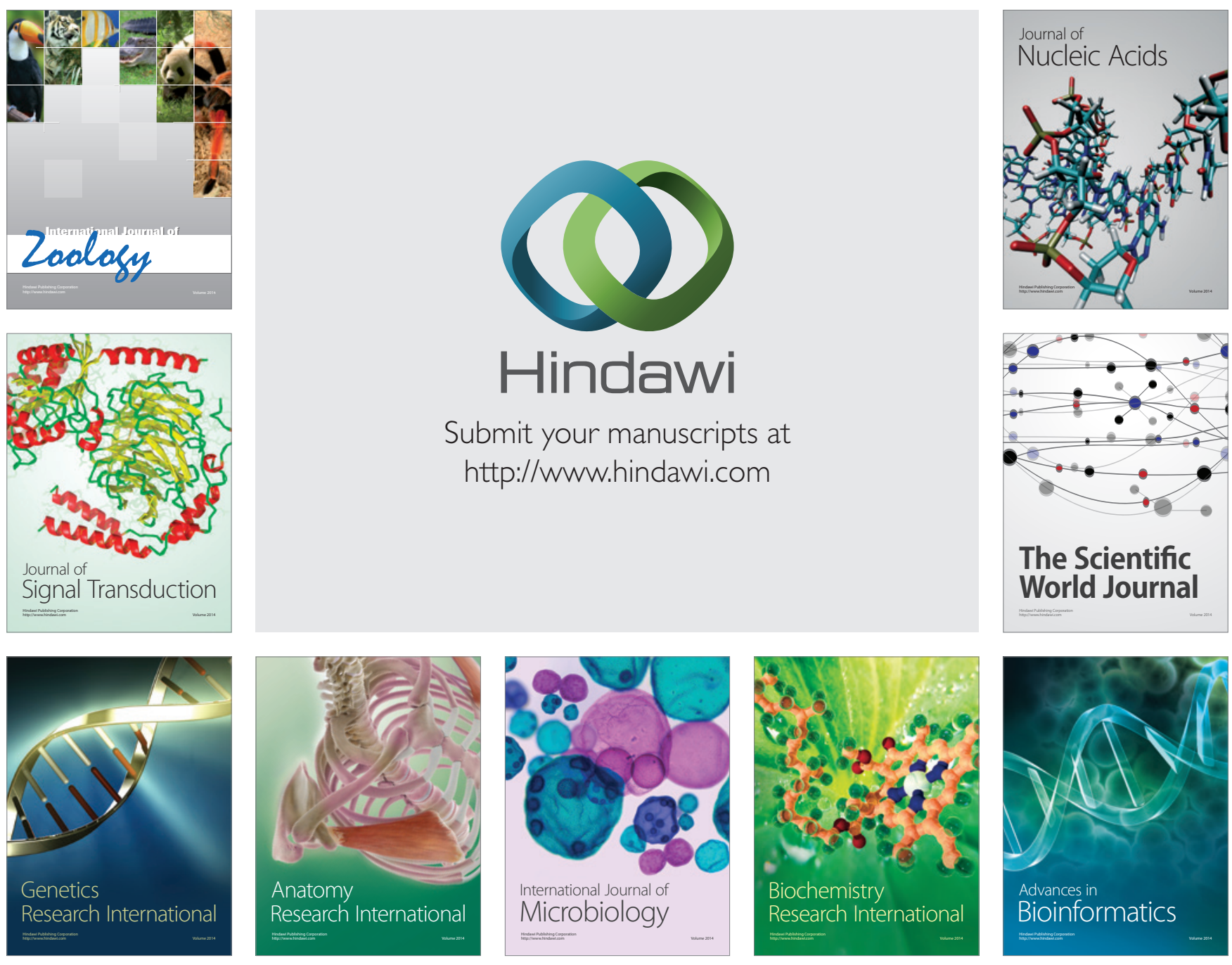

The Scientific World Journal
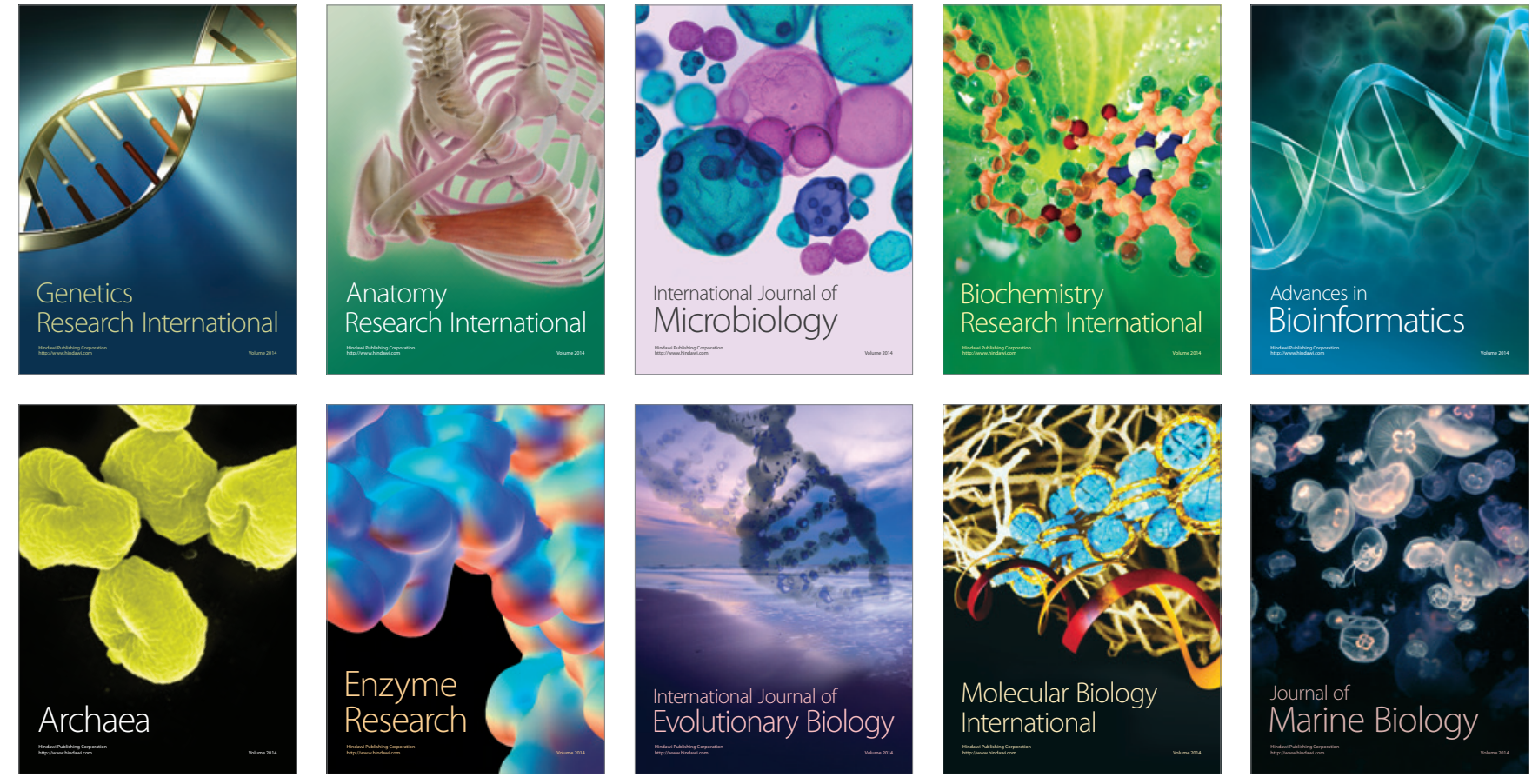